\title{
Effect of Restricted Irrigation on Water Relation Traits and Antioxidant Activity
}

\author{
Rajkumar*, Kirpa Ram, Sapna and Kamal Dutt Sharma \\ Department of Botany and Plant Physiology, \\ CCS Haryana Agricultural University, Hisar -125 004, India \\ *Corresponding author
}

\section{Keywords \\ Barley, Drought, Antioxidant and plant water relation traits}

Article Info

Accepted: 04 March 2018 Available Online: 10 April 2018

\section{A B S T R A C T}

\begin{abstract}
Water relation traits and antioxidant metabolism play a very imperative role in barley growth and productivity when crop imposed under restricted irrigation. Present investigation was planned to study the responses to water status and antioxidant mechanism under normal (irrigated) and drought (restricted irrigation) condition. Twenty barley genotypes were cultivated under irrigated (Two irrigations at tillering and anthesis each) and limited irrigation conditions (one irrigation at tillering) in concrete drought plots during the 2014-15 and 2015-16 growing seasons at the Crop physiology field area, Hisar. The experiments were laid out using RBD with three replications. The results from combined analysis of variance in both normal and drought conditions indicated that there were significant differences among genotypes with regard to all studied traits which were due to high variation among the genotypes. Limited irrigation significantly decreased the plant leaf water potential, leaf osmotic potential and relative water content while increased membrane injury in all barley genotypes studies. It was found that the activity of enzymes including superoxide dismutase (SOD), catalase (CAT) and peroxidase (POX) were increased under drought stress conditions, so that tolerant genotypes had more changes in enzyme activity. Genotypes BH 14-05 and BH-10-30 in present study were found better antioxidant activity and maintained plant water status among all the genotypes under both normal and restricted irrigation condition and vice-versa. These genotypes because of better plant water status and antioxidant activity were found maximum in grain yield.
\end{abstract}

\section{Introduction}

Barley (Hordeum vulgare L.) is oldest domesticated cereals crops of world agriculture and stand fourth major ranked crop in the worldwide production of cereals. Barley is an important cereal crop targeted for animal feed (Jacob and Pescatore 2012) malting and industrial purposes while $2 \%$ is used for human consumption (Baik and Ullrich 2008). This crop mostly grown under rainfed conditions, where drought and heat stress usually constrain yield during the grain filling period (Dorostkar et al. 2015). Water deficit or drought stress is one of the most common environmental stresses that affects growth and development of plants (Abarshahr et al., 2011).

Water status of a crop plant is usually 
expressed in terms of relative amount of water content, water potential and osmotic potential (Sabir et al. 2008; Javed et al. 2011). During water stress reduction was found between osmotic potential (Zhang et al. (2015), water potential (Iqubal et al. (2014) and relative water content (Vaezi et al. 2010) in barley genotypes (Sharma et al., 2016; Aboughadareh et al. 2017). When plant expose to adverse environment (drought) reactive oxygen species (ROS) such as superoxide $\left(\mathrm{O}_{2}{ }^{\circ}\right)$, hydrogen peroxide $\left(\mathrm{H}_{2} \mathrm{O}_{2}\right)$, hydroxyl radicals $\left(\mathrm{OH}^{\circ}\right)$ and singlet oxygen $\left({ }^{1} \mathrm{O}_{2}\right)$ are produced (Faize et al. 2011). Multiple antioxidant enzymes like superoxide dismutases (SOD), catalases (CAT) and peroxidases (POX) are involved in the enzymatic scavenging of ROS (Apel and Hirt, 2004; de Carvalho, 2008; Farooq et al. 2009).

The accumulation of ROS is defend by superoxide dismutase (SOD), which dismutates the $\mathrm{O}^{-}$radicals to $\mathrm{H}_{2} \mathrm{O}_{2}$ (de Carvalho, 2008). Catalase (CAT) and ascorbate peroxidase (APX) are two enzymes that scavenge $\mathrm{H}_{2} \mathrm{O}_{2}$ and prevent its accumulation to toxic levels. Peroxidase on other hand is an oxidoreductase that causes $\mathrm{H}_{2} \mathrm{O}_{2}$ breakdown (Jiang and Jhang, 2004). In a field study, it was observed that when crop genotypes are subjected to restricted irrigation at different growth stage, the drought-tolerant genotypes acclimatized better than the drought-susceptible cultivar by conserving water relations and accumulation antioxidant defense enzyme in the leaves (Ranjeet et al. 2012).

Therefore, the present study aimed to determine the effect drought stress on enzymatic antioxidant systems including superoxide dismutase, catalases and peroxidases and plant water relation traits of barley genotypes.

Materials and Methods

\section{Plant material and experimental site}

Twenty barley genotypes viz. $\mathrm{BH}$ 07-35, BH 10-30, BH 12-17, BH 12-20, BH 12-29, BH 12-46, BH 13-10, BH 13-21, BH 13-22, BH 13-23, BH 14-01, BH 14-05, BH 14-06, BH 14-07, BH 14-08, BH 14-09, BH 14-10, BH 14-11, BH 902 (check) and BH 946 (check) were grown in concrete drought plots $(6 \mathrm{~m} \times$ $45 \mathrm{~m}$ ) with rainout shelters facilities and filled with dunal sand located at Crop Physiology Field Area of Department of Agronomy, CCS Haryana Agricultural University, Hisar. The plot size for each genotype was $2.5 \times 1.5 \mathrm{~m}(5$ rows of $5 \mathrm{~m}$ length with $30 \mathrm{~cm}$ spacing). The experiment was laid out in RBD (Randomized Block Design) with three replications.

\section{Water relation traits}

Relative water content (RWC) of fully expended flag leaf was measured by the used the method of Barrs aand Weatherley (1962).

Water potential $\left(\Psi_{\mathrm{w}}\right)$ in flag leaf was measured with the help of pressure chamber (Model 3005, Soil Moisture Equipment Corporation, Santa Barbara, CA, USA), between 8 to $10 \mathrm{AM}$. The osmotic potential of leaf was estimated by the method of Morgan (1980) with psychrometric technique using vapour pressure osmometer (Wescor INC., Lorganan, Utah, USA).

\section{Antioxidant enzymes}

\section{Preparation of enzyme extract}

One-gram leaf sample were homogenized in 4 $\mathrm{ml}$ of $0.1 \mathrm{M}$ phosphate buffer $(\mathrm{pH} 7.0)$ contains $1 \%$ polyvinyl pyrrolidine and centrifuged at $10,000 \mathrm{x} \mathrm{g}$ for $20 \mathrm{~min}$. in a refrigerated centrifuge at $4^{0} \mathrm{C}$. The supernatant was used for determining the activity of superoxide dismutase (SOD), catalase (CAT) and 
peroxidise (POX).

Superoxide dismutase was assayed by measuring its ability to inhibit the photochemical reduction of nitro blue tetrazolium (NBT) adopting the method of Beauchamp and Fridovich (1971). Per cent inhibition was calculated by following formula of Asada et al. (1974):

Percent inhibition $=\frac{(\mathrm{V}-\mathrm{v})}{\mathrm{v}} \times 100$

Where,

$\mathrm{V}=\quad$ Rate of assay reaction in absence of SOD, $v=$ Rate of assay reaction in presence of SOD.

One enzyme unit is defined as the amount of enzyme that inhibits the nitro blue tetrazolium photoreduction by $50 \%$.

Catalase activity was measured according to the method of Sinha, (1972). One unit of enzyme activity is defined as the amount of enzyme which catalyzed the oxidation of $1 \mu$ mole $\mathrm{H}_{2} \mathrm{O}_{2}$ per min. under assay conditions.

Peroxidase activity was assayed by adopting the method of Shannon et al. (1966). One unit of peroxidase represents 1.0 O.D. change per $\min$.

\section{Results and discussion}

\section{Water relation traits}

Leaf water potential, osmotic potential and relative water content showed a decreasing trend under restricted irrigation condition among all genotypes as compared to normal irrigation condition at both stages (flag leaf and anthesis) of observation (Table 1).

\section{Water potential (-MPa)}

Drought at flag leaf and anthesis stage reduced water potential in flag leaf. Reduction in water potential was more at anthesis as compare to flag leaf stage under normal and restricted irrigation condition respectively. Average water potential for different genotypes for normal irrigation ranged from -1.44 to -1.88 $\mathrm{MPa}$ (flag leaf) and -1.44 to $-1.87 \mathrm{MPa}$ (anthesis) whereas, for restricted irrigation water potential value varied between -1.65 to 2.25 MPa (flag leaf) and -1.95 to $-2.68 \mathrm{MPa}$ (anthesis). Average water potential at flag leaf was -1.64 and $-1.65 \mathrm{MPa}$ and at anthesis -1.90 and $-2.33 \mathrm{MPa}$ under normal and restricted irrigation condition respectively. Genotype BH 14-08 and BH 13-10 had maximum water potential at both growth stage flag leaf and anthesis respectively. Our finding is accordance with those of Ahmed et al. (2013) and Liu et al. (2015) observed reduction in water potential when crop was imposed under drought environment. Water stressed plants showed a significant reduction in leaf water potential than non-water stressed plants (Pang et al. 2016).

\section{Osmotic potential (-MPa)}

Results presented in table showed of osmotic potential flag leaf and anthesis under normal and restricted irrigation condition. Average osmotic potential for different genotypes for normal irrigation ranged from -0.29 to -1.67 $\mathrm{MPa}$ (flag leaf) and -0.30 to $-1.67 \mathrm{MPa}$ (anthesis) whereas, for restricted irrigation OP value varied between -0.63 to $-1.72 \mathrm{MPa}$ (flag leaf) and -1.51 to $-2.01 \mathrm{MPa}$ (anthesis). Average osmotic potential at flag leaf was 0.87 and $-0.90 \mathrm{MPa}$ and at anthesis -1.17 and $1.75 \mathrm{MPa}$ under normal and restricted irrigation condition respectively. Genotype BH 14-08 and BH 13-10 had maximum osmotic potential at both growth stage flag leaf and anthesis respectively.

Our results are in agreement with those of 
Sharma et al. (2016) in barley and Ram et al. 2017 in wheat found decrease in osmotic potential on the onset of stress. Hein et al. (2016) also observed significant difference in osmotic potential between drought and in control plants, OP was lowest in the flag leaf, whereas after the 4-days drought treatment, OP had dropped subsequently in the flag leaf.

Table.1 Effect of restricted irrigation on leaf water potential, osmotic potential and relative water content at flag leaf and anthesis in barley genotypes

\begin{tabular}{|c|c|c|c|c|c|c|c|c|c|c|c|c|}
\hline \multirow{3}{*}{ Genotypes } & \multicolumn{4}{|c|}{ Water potential (-MPa) } & \multicolumn{4}{|c|}{ Osmotic potential (-MPa) } & \multicolumn{4}{|c|}{ Relative water content (\%) } \\
\hline & \multicolumn{2}{|c|}{ Flag leaf } & \multicolumn{2}{|c|}{ Anthesis } & \multicolumn{2}{|c|}{ Flag leaf } & \multirow[b]{2}{*}{ NI } & \multirow[b]{3}{*}{ ВН07-35 } & \multicolumn{2}{|c|}{ Flag leaf } & \multicolumn{2}{|c|}{ Anthesis } \\
\hline & NI & RI & NI & & NI & RI & & & NI & RI & NI & \\
\hline ВH07-35 & 1.53 & 1.55 & 1.68 & ВH07-35 & 1.53 & 1.55 & 1.68 & & 1.53 & 1.55 & 1.68 & ВH07-35 \\
\hline BH10-30 & 1.48 & 1.49 & 1.65 & BH10-30 & 1.48 & 1.49 & 1.65 & ВH10-30 & 1.48 & 1.49 & 1.65 & BH10-30 \\
\hline BH12-17 & 1.60 & 1.60 & 1.93 & BH12-17 & 1.60 & 1.60 & 1.93 & BH12-17 & 1.60 & 1.60 & 1.93 & BH12-17 \\
\hline BH12-20 & 1.61 & 1.61 & 1.94 & BH12-20 & 1.61 & 1.61 & 1.94 & BH12-20 & 1.61 & 1.61 & 1.94 & BH12-20 \\
\hline ВH12-29 & 1.49 & 1.50 & 1.67 & BH12-29 & 1.49 & 1.50 & 1.67 & ВH12-29 & 1.49 & 1.50 & 1.67 & BH12-29 \\
\hline BH12-46 & 1.72 & 1.72 & 1.95 & BH12-46 & 1.72 & 1.72 & 1.95 & ВH12-46 & 1.72 & 1.72 & 1.95 & BH12-46 \\
\hline BH13-10 & 1.80 & 1.80 & 2.04 & BH13-10 & 1.80 & 1.80 & 2.04 & BH13-10 & 1.80 & 1.80 & 2.04 & BH13-10 \\
\hline ВН13-21 & 1.70 & 1.71 & 2.02 & BH13-21 & 1.70 & 1.71 & 2.02 & ВH13-21 & 1.70 & 1.71 & 2.02 & BH13-21 \\
\hline BH13-22 & 1.72 & 1.72 & 1.94 & BH13-22 & 1.72 & 1.72 & 1.94 & BH13-22 & 1.72 & 1.72 & 1.94 & BH13-22 \\
\hline BH13-23 & 1.74 & 1.74 & 2.05 & BH13-23 & 1.74 & 1.74 & 2.05 & BH13-23 & 1.74 & 1.74 & 2.05 & BH13-23 \\
\hline BH14-01 & 1.75 & 1.76 & 1.98 & BH14-01 & 1.75 & 1.76 & 1.98 & BH14-01 & 1.75 & 1.76 & 1.98 & BH14-01 \\
\hline BH14-05 & 1.49 & 1.49 & 1.65 & BH14-05 & 1.49 & 1.49 & 1.65 & BH14-05 & 1.49 & 1.49 & 1.65 & BH14-05 \\
\hline BH14-06 & 1.76 & 1.77 & 1.98 & BH14-06 & 1.76 & 1.77 & 1.98 & BH14-06 & 1.76 & 1.77 & 1.98 & BH14-06 \\
\hline BH14-07 & 1.47 & 1.49 & 1.70 & BH14-07 & 1.47 & 1.49 & 1.70 & BH14-07 & 1.47 & 1.49 & 1.70 & BH14-07 \\
\hline BH14-08 & 1.80 & 1.79 & 2.12 & BH14-08 & 1.80 & 1.79 & 2.12 & BH14-08 & 1.80 & 1.79 & 2.12 & BH14-08 \\
\hline BH14-09 & 1.88 & 1.87 & 2.11 & BH14-09 & 1.88 & 1.87 & 2.11 & BH14-09 & 1.88 & 1.87 & 2.11 & BH14-09 \\
\hline BH14-10 & 1.44 & 1.44 & 1.69 & BH14-10 & 1.44 & 1.44 & 1.69 & BH14-10 & 1.44 & 1.44 & 1.69 & BH14-10 \\
\hline BH14-11 & 1.73 & 1.75 & 2.25 & BH14-11 & 1.73 & 1.75 & 2.25 & BH14-11 & 1.73 & 1.75 & 2.25 & BH14-11 \\
\hline BH902 & 1.59 & 1.57 & 1.83 & BH902 & 1.59 & 1.57 & 1.83 & BH902 & 1.59 & 1.57 & 1.83 & BH902 \\
\hline BH946 & 1.56 & 1.56 & 1.86 & BH946 & 1.56 & 1.56 & 1.86 & BH946 & 1.56 & 1.56 & 1.86 & BH946 \\
\hline Mean & 1.64 & 1.65 & 1.90 & Mean & 1.64 & 1.65 & 1.90 & Mean & 1.64 & 1.65 & 1.90 & Mean \\
\hline \multirow{4}{*}{ CD at $5 \%$} & $\mathbf{E}=0.014$ & \multicolumn{3}{|c|}{$\mathbf{E x S}=0.021$} & $\mathbf{E}=0.008$ & \multicolumn{3}{|c|}{ CD at $5 \%$} & $\mathbf{E}=0.014$ & \multicolumn{3}{|c|}{$\mathbf{E x S}=0.021$} \\
\hline & $\mathbf{S}=0.020$ & \multicolumn{3}{|c|}{$\mathbf{E x G}=0.063$} & $\mathbf{S}=0.008$ & & & & $\mathbf{S}=0.020$ & \multicolumn{3}{|c|}{$\mathbf{E x G}=0.063$} \\
\hline & $\mathbf{G}=0.045$ & \multicolumn{3}{|c|}{$\mathbf{S x G}=\mathrm{NS}$} & $\mathbf{G}=0.025$ & & & & $\mathbf{G}=0.045$ & \multicolumn{3}{|c|}{$\mathbf{S x G}=\mathrm{NS}$} \\
\hline & \multicolumn{4}{|c|}{$\mathbf{E x S x G}=\mathrm{NS}$} & \multicolumn{4}{|c|}{$\mathbf{E x S x G}=0.050$} & \multicolumn{4}{|c|}{$\mathbf{E x S x G}=\mathrm{NS}$} \\
\hline
\end{tabular}

$\mathrm{NI}=$ Normal irrigation, $\mathrm{RI}=$ Restricted irrigation, $\mathrm{E}=$ Environment, $\mathrm{S}=$ Stage and $\mathrm{G}=$ Genotypes 
Fig.1 Effect of restricted irrigation on superoxide dismutase specific activity at flag leaf stage and anthesis in barley genotypes

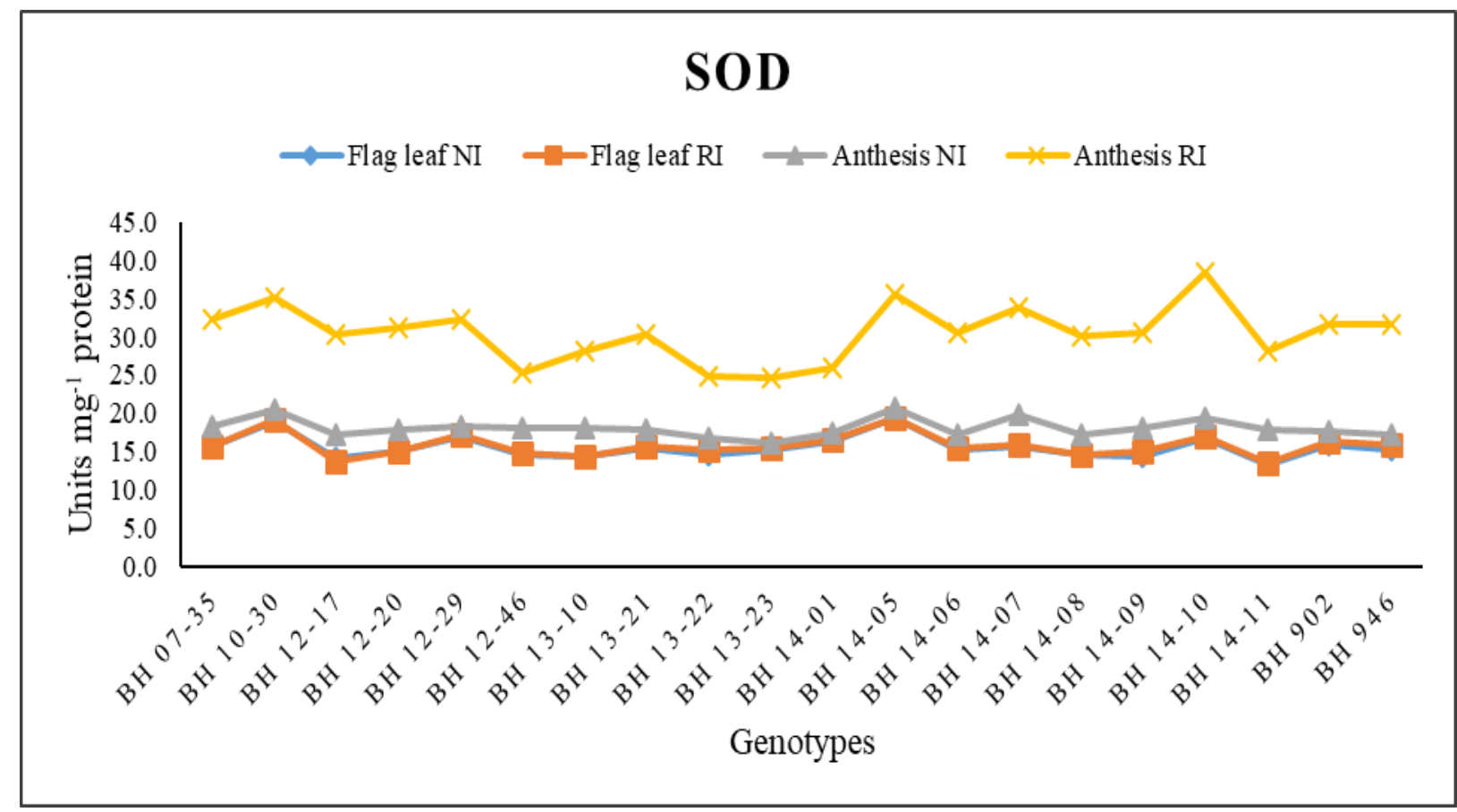

NI= Normal irrigation and RI= Restricted irrigation

Fig.2 Effect of restricted irrigation on catalase specific activity at flag leaf stage and anthesis in barley genotypes

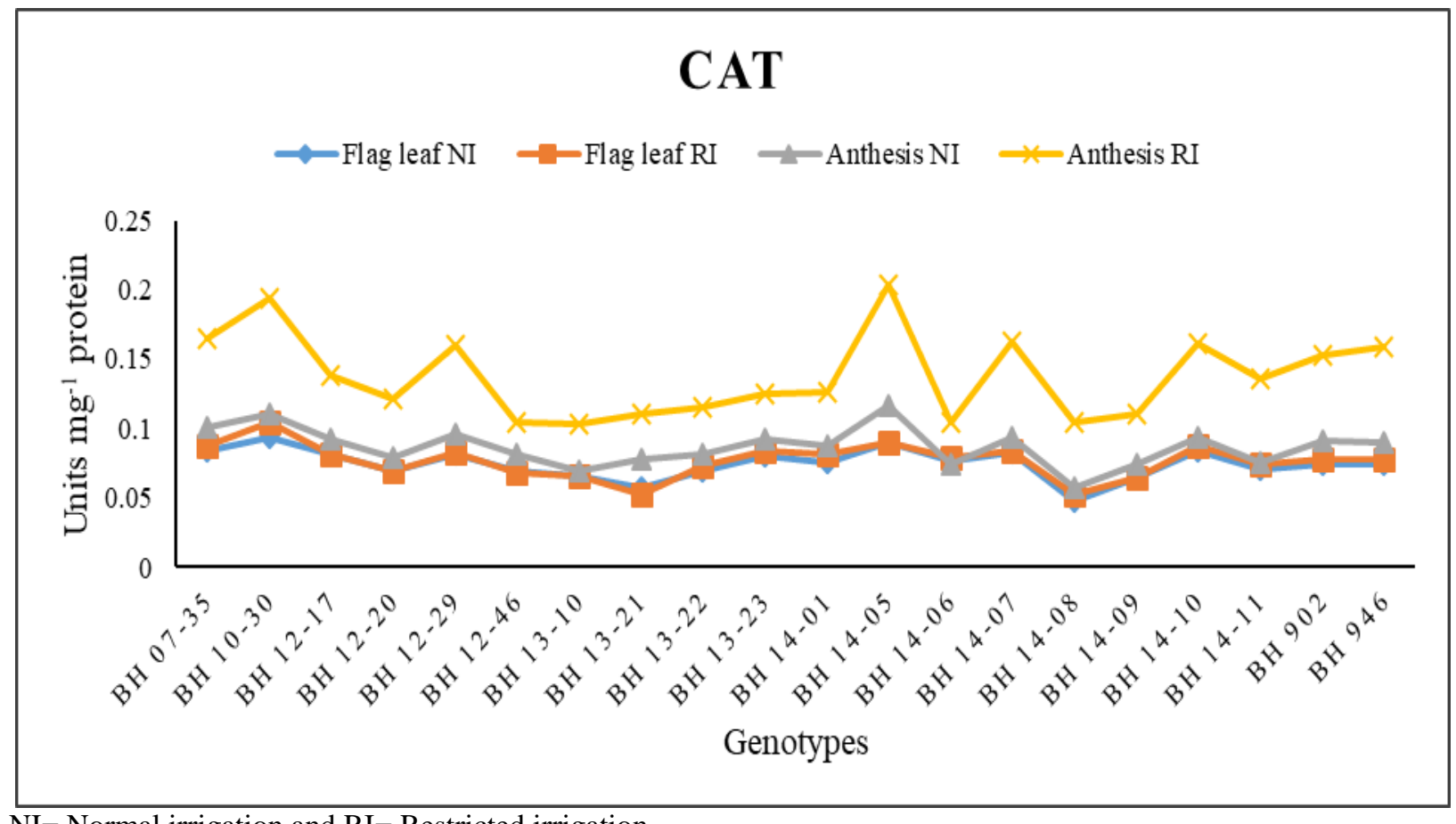

$\mathrm{NI}=$ Normal irrigation and $\mathrm{RI}=$ Restricted irrigation 
Fig.3 Effect of restricted irrigation on peroxidase specific activity at flag leaf stage and anthesis in barley genotypes

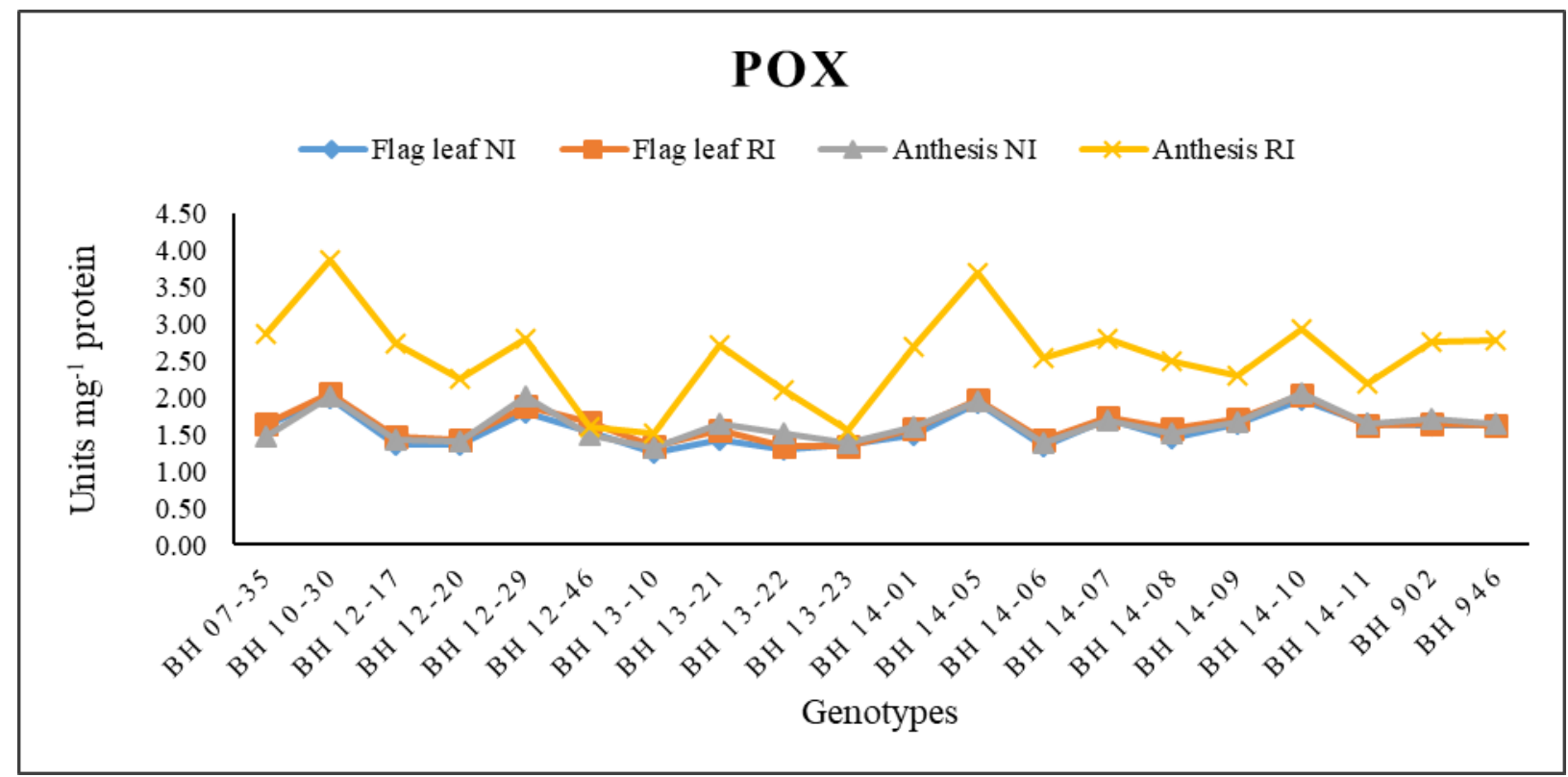

$\mathrm{NI}=$ Normal irrigation and $\mathrm{RI}=$ Restricted irrigation

\section{Relative water content (\%)}

Reduction in leaf relative water content at flag leaf and anthesis was observed under restricted irrigation condition as compare to normal irrigation. Maximum reduction noticed at anthesis compared to flag leaf at restricted irrigation condition. Average relative water content for different genotypes for normal irrigation ranged from 72.2 to 80.9 $\%$ (flag leaf) and 70.7 to $79.2 \%$ (anthesis) whereas, for restricted irrigation relative water content value varied between 78.1 to $84.1 \%$ (flag leaf) and 58.8 to $72.9 \%$ (anthesis). Average relative water content at flag leaf was 76.4 and $75.2 \%$ and at anthesis 80.9 and $65.6 \%$ under normal and restricted irrigation condition respectively. Genotype $\mathrm{BH}$ 14-08 and $\mathrm{BH}$ 13-10 had maximum relative water content at both growth stage flag leaf and anthesis respectively. Our finding is accordance with those of Kumar and Sharma, (2010) and Sharma et al. (2016) observed reduction in relative water content when crop was imposed under drought environment. Karami et al. 2013 find genotype whose maintain water status had more in antioxidant activity under drought condition.

Behbahanizadeh, et al. (2014) and Ram et al. (2017) also reported that under drought stress conditions (moderate stress and severe stress) RWC, osmotic potential and water potential reduced in contrast to control condition and cultivars had a significant difference together in water relation traits.

\section{Antioxidant enzymes}

\section{Superoxide dismutase specific activity}

Figure 1 showed superoxide dismutase (SOD) specific activity under normal and restricted irrigation condition at flag leaf and anthesis in graphical representation. SOD activity significantly increased from flag leaf stage to 
anthesis stage. At flag leaf maximum increase in SOD activity was found in $\mathrm{BH}$ 14-09 (4.4\%) and $\mathrm{BH} 13-09$ (3.6\%) and at anthesis in $\mathrm{BH} 946$ (41.4\%) and $\mathrm{BH} 14-06$ (38.4\%) under restricted irrigation condition, whereas, minimum increase in $\mathrm{BH} 12-46$ (19.7\%) and BH 14-01 (24.9\%) at anthesis. Genotypes BH 14-05 and $\mathrm{BH}$ 10-30 had maximum in specific SOD activity at flag leaf and anthesis under both environments. The outcome from this study is lined with the results of Acar et al. (2001) and Salekjalali et al. (2012) in barley, SOD activity was increased in drought-resistant genotypes under progressive drought.

\section{Catalase specific activity}

The CAT activity was found to be higher in genotypes $\mathrm{BH} \quad 10-30$ and $\mathrm{BH}$ 14-05, respectively, at both the growth stages under normal irrigation condition (Figure 2). Minimum CAT activity was observed in $\mathrm{BH}$ 14-08 at both the stages of growth observation under normal and restricted irrigation. Maximum increase in CAT activity was observed in BH 13-23 (133.4\%) and BH 14$08(80.3 \%)$ at flag leaf and at anthesis in $\mathrm{BH}$ $10-30(12.9 \%)$ and $\mathrm{BH} 07-35$ (11.7\%) under restricted irrigation. Minimum increase in CAT activity was observed in $\mathrm{BH}$ 12-46 (27.6\%) and $\mathrm{BH} 07-35(38.7 \%)$ at anthesis under restricted irrigation condition. Our results are consistent with Kolarovic et al. (2009); Luna et al. (2004) and Sharma and Dubey (2005) reported a decrease in CAT activity under drought stress in different cereal crops.

\section{Superoxide dismutase specific activity}

The POX specific activity increased from $3.56 \%$ to $31.73 \%$ from flag leaf to anthesis stage under restricted irrigation condition (Figure 3). Among the genotypes higher POX activity was observed in $\mathrm{BH} 10-30$, BH 14-10 and $\mathrm{BH}$ 14-05 in both irrigation environments and growth stage. Under restricted irrigation condition maximum increase in enzyme specific activity among genotypes was observed in $\mathrm{BH} 14-08(9.1 \%)$ and $\mathrm{BH} 13-21$ $(9.0 \%)$ at flag leaf and $\mathrm{BH} 07-35(94.8 \%), \mathrm{BH}$ $12-17$ (92.9\%) and $\mathrm{BH} 10-30$ (91.9\%) at anthesis while minimum increase in $\mathrm{BH}$ 12$46(0.6 \%)$ and $\mathrm{BH} 14-11(34.2 \%)$ at anthesis stage of observation. The interaction among all factors taken into consideration was found to be significant at each growth stage. Our result is accordance with the study of Sairam and Saxena (2000); Shao et al. (2005) and Chugh et al. (2011). Cultivar exhibited a higher CAT activity compared to another found tolerant under drought condition (Valifard et al. 2012).

In conclusion selection for best and promising genotype for adverse environment using physiological and biochemical traits is the best way of selection. The genotype BH 1405 and $\mathrm{BH}$ 10-30 had higher antioxidant activity (SOD, CAT and POX) and maximum in water relation traits compared to among all genotypes. These genotypes further used as to improved physiological and biochemical processes to produced more grain yield.

\section{References}

Abarshahr, M., Rabiei, B. and Samizadeh, L.H. (2011) Assessing genetic diversity of rice varieties under drought stress conditions. Notulae Scientia Biologicae, 3(1), 114-123.

Aboughadareh, A.P., Ahmadi, J., Mehrabi, A.A., Etminan, A., Moghaddam, M. and Siddiqu, K.H.M. (2017) Physiological responses to drought stress in wild relatives of wheat: implications for wheat improvement. Acta Physiologaie Plantarum, 39,106. 
Acar, O., Tiirkan, I. and Ozdemir, F (2001) Superoxide dismutase and peroxidase activities in drought sensitive and resistant barley (Hordeum vulgare L.) varieties. Acta Physiologiae Plantarum, 23, 351-356.

Ahmed, I.M., Dai, H., Zheng, W., Cao, F., Zhang, G., Sun, D. and Wu, F. (2013) Genotypic differences in physiological characteristics in the tolerance to drought and salinity combined stress between Tibetan wild and cultivated barley. Plant Physiology and Biochemistry, 63, 49-60.

Apel, K. \& Hirt, H. (2004) Reactive oxygen species: metabolism, oxidative stress, and signal transduction. Annual Review Plant Biology, 55, 373-399.

Baik, B-K. \& Ullrich, S.E. (2008) Barley for food: characteristics, improvement, and renewed interest. J Cereal Sci 48, 233242.

Barrs, H.D. and Weatherley, P.E. (1962) A reexamination of the relative turgidity technique for estimating water deficits in leaves. Australian Journal of Biological Sciences, 15, 413-428.

Beauchamp, C. and Fridovich, I. (1971) Superoxide dismutase: Improved assay and an assay applicable to acrylamide gels. Journal of Analytical Biochemistry, 44, 276-287.

Behbahanizadeh, S.A., Akbari, G.A., Shahbazi, M. and Alahdadi, I. (2014) Relations between Barley Root Traits and Osmotic Adjustment under Terminal Drought Stress. Journal of Agricultural Science, 6(7).

Chugh, V., Kaur, N. and Gupta, A.K. (2011) Evaluation of oxidative stress tolerance in maize (Zea mays L.) seedlings in response to drought. Indian Journal of Biochemistry and Biophysics, 48, 4753.

De Carvalho, M.C. (2008) Drought stress and reactive oxygen species: production, scavenging and signaling. Plant Signaling Behaviour, (3), 156-165.

Dorostkar, S., Dadkhodaie, A., \& Heidari, B. (2015). Evaluation of grain yield indices in hexaploid wheat genotypes in response to drought stress. Archives of Agronomy and Soil Science, 61, 397413.

Faize, M., Burgos, L., Faize, L., Piqueras, A., Nicolas, E., Barba-Espin, G., ClementeMoreno, M.J., Alcobendas, R., Artlip, T. \& Hernandez, J.A. (2011) Involvement of cytosolic ascorbate peroxidase and $\mathrm{Cu} / \mathrm{Zn}$-superoxide dismutase for improved tolerance against drought stress. Journal of Experimental Botany, 62, 2599-2613.

Farooq, M., Wahid, A., Kobayashi, N., Fujita, D. and Basra, S.M.A. (2009) Plant drought stress: Effects, mechanisms and management. Agronomy for Sustainable Development, 29(1), 185-212.

Hein, J.A., Sherrard, M.E., Manfredi, K.P. and Abebe, T. (2016) The fifth leaf and spike organs of barley (Hordeum vulgare L.) display different physiological and metabolic responses to drought stress. Biomedical Plant Biology, 16, 248-252.

Iqbal, M.Y., Ashraf, M., Akram, N.A., AlQurainy, F. and Jones, M.G. (2014) Biomass and some key physiological markers as selection criteria for drought tolerance in barley (Hordeum vulgare L.). Journal of Agricultural Science, 7(1), 49-57.

Jacob, J.P. \& Pescatore, A.J. (2012) Using barley (Hordeum vulgare L) in poultry diets-A review. J Appl Poult Res 21, 915-940.

Javed, N., Ashraf, M., Akram N.A., et al., (2011) Alleviation of adverse effects of drought stress on growth and some potential physiological attributes in maize (Zea maize L.) by seed electromagnetic treatment. Journal of 
Photochemistry and Photobiology, 87, 1354-1362.

Jiang, M.Y. and Jhang, J.H. (2004) Absicsic acid and antioxidant defense in plant cells. Acta Botanica Sinica, 46, 1-9.

Karami, A., Shahbazi, M., Niknam, V., Shobbar, Z., Tafreshi, R.S. and Abedini, R. (2013) Expression analysis of dehydrin multigene family across tolerant and susceptible barley (Hordeum vulgare L.) genotypes in response to terminal drought stress. Acta Physiologiae Plantarum, 35, 22892297.

Kolarovic, L., Valentovic, P., Luxova, M. \& Gasparıkova, O. (2009) Changes in antioxidants and cell damage in heterotrophic maize seedlings differing in drought sensitivity after exposure to short-term osmotic stress. Plant Growth Regulator, 59, 21-26.

Kumar, A. and Sharma, K.D. (2010) Leaf water content-a simple indicator of drought tolerance in crop plants. The Indian Journal of Agricultural Science, 80, 1095-1097.

Liu, H., Searle, I.R., Mather, D.E., Able, A.J. and Able, J.A. (2015) Morphological, physiological and yield responses of durum wheat to pre-anthesis waterdeficit stress are genotype-dependent. Crop and Pasture Science, 66, 10241038.

Luna, C. M., Pastori, G.M., Driscoll, S., Groten, K., Bernard, S. and Foyer, C.H. (2004) Drought controls on $\mathrm{H} 2 \mathrm{O} 2$ accumulation, catalase (CAT) activity and CAT gene expression in wheat. Journal of Experimental Botany, 56, 417-423.

Pang, J., Turner, N.C., Khan, T., Du, Y.L., Xiong, J.L., Colmer, T.D., Devilla, R., Stefanova, K. and Siddique, K.H.M. (2016) Response of chickpea (Cicer arietinum L.) to terminal drought: leaf stomatal conductance, pod abscisic acid concentration, and seed set. Journal of Experimental Botany, 68, 1973-1985.

Ram, K., Munjal, R., Sunita \& Kumar, N. (2017) Combine Effects of Drought and High Temperature on Water Relation Traits in Wheat Genotypes under Late and Very Late Sown Condition. International Journal of Current Microbiology and Applied science, 6(8), 567-576.

Ranjeet, Kumar, R., Sharma, S.K., Kritika, Gadpayle, A., Singh, K., Sivaranjani R., Goswami, S. and Rai R.D. (2012) Mechanism of action of hydrogen peroxide in wheat thermotolerance interaction between antioxidant isoenzymes, proline and cell membrane. African Journal of Biotechnology, 11(78), 14368-14379.

Sabir, P. and Ashraf, M. (2008) Inter-cultivar variation for salt tolerance in proso millet (Panicum miliaceum L.) at the germination stage. Pakistan Journal of Botany, 40, 677-682.

Sairam, R.K. \& Saxena, D.C. (2000) Oxidative stress and antioxidant in wheat genotypes: possible mechanism of water stress tolerance. Journal of Agronomy Crop Sciences, 184, 55-61.

Salekjalali, M., Haddad, R. and Jafari, B. (2012) Effects of soil water shortages on the activity of antioxidant enzymes and the contents of chlorophylls and proteins in barley. American-Eurasian Journal of Agricultural and Environmental Science, 12(1), 57-63.

Shannon, L.M., Key, E. and Law, J.Y. (1966) Peroxidase isoenzymes from horse reddish roots: Isolation and physical properties. Journal of Biological Chemistry, 241, 2166-2172.

Shao, H.B., Liang, Z.S. \& Shao, M.A. (2005) Changes of some anti-oxidative enzymes under soil water deficits among 10 wheat genotypes at 
maturation stage. Colloids and Surfaces B: Biointerfaces, 45, 7-13.

Sharma, K.D., Kumar, A. and Verma, S.R. (2016) Variations in physiological traits as screening tool for drought tolerance in barley (Hordeum vulgare L.). Indian Journal of Plant Physiology, 21(1), 93100.

Sharma, P. \& Dubey, R.S. (2005) Modulation of nitrate reductase activity in rice seedlings under aluminium toxicity and water stress: role of osmolytes as enzyme protectant. Journal of Plant Physiology, 162, 854-864.

Sinha, A.K. (1972) Calorimetric assay of catalase. Journal of Analytical Biochemistry, 47, 389-395.

Vaezi, B., Bavei, V. and Shiran, B. (2010) Screening of barley genotypes for drought tolerance by agro-physiological traits in field condition. African Journal of Agricultural Research, 5(9), 881-892. Valifard, M., Moradshahi, A. \& Kholdebarin, B. (2012) Biochemical and physiological responses of two wheat (Triticum aestivum L.) cultivars to drought stress applied at seedling stage. Journal of Agricultural Sciences and Technology, 14, 1567-1578.

Zhang, Y., Yao, Q., Li, J., Wang, Y., Liu, X., $\mathrm{Hu}, \mathrm{Y}$., et al., (2015) Contributions of an arbuscular mycorrhizal fungus to growth and physiology of loquat (Eriobotrya Japonica) plants subjected to drought stress. Mycological Progress, 14,84 .

\section{How to cite this article:}

Rajkumar, Kamal Dutt Sharma, Sapna and Kirpa Ram. 2018. Effect of Restricted Irrigation on Water Relation Traits and Antioxidant Activity. Int.J.Curr.Microbiol.App.Sci. 7(04): 424-433. doi: https://doi.org/10.20546/ijcmas.2018.704.049 